\title{
PENYULUHAN LABORATORIUM LAPANGAN BUDIDAYA TERONG DAN CABE DI KELURAHAN BANDAR BATAUGA KECAMATAN BATAUGA KABUPATEN BUTON SELATAN
}

\author{
Wa Ode Alzarliani, La Ode Muhammad Mustari, Antasalam Ajo, Hardin, Azelia Monica A. ${ }^{\text {1) }}$ \\ Fakultas Pertanian Universitas Muhammadiyah Buton \\ Jln. Betoambari No. 36 Kota Baubau, 93721 Indonesia \\ Email: 1mmustari74@yahoo.co.id
}

\begin{abstract}
Abstrak
Kegiatan Laboratorium lapang Hortikultura sangat diperlukan untuk mendukung Visi Fakultas Pertanian Universitas Muhammadiyah Buton, laboratorium lapang tersebut selain sebagai pendukung PBM (proses belajar mengajar) dan pengabdian kepada masyarakat, juga dapat dijadikan sebagai etalase (show window). Keberadaan laboratorium lapang ini diharapkan dapat membangun image baru pada bidang pertanian, khususnya bagi generasi muda, bahwa bidang pertanian tidak kalah dengan bidang yang lain, dapat menjadi profesi yang menarik, prospektif, dan terhormat. Dari hasil penelitian sebelumnya, laboratorium lapang mempunyai kelas lereng yang sangat beragam. Secara umum, didominasi oleh lereng agak miring/bergelombang dengan lereng (8-15\%) dengan luas lebih dari 50\% laboratorium lapang. Laboratorium lapang terpadu, dengan luas lebih kurang 0,5 ha. Tujuan kegiatan Penyuluhan Laboratorium Lapangan ini adalah meningkatkan pengetahuan petani tentang budidaya terong dan cabe dan peningkatan kesejahteraan petani terong dan cabe. Pelaksanaan kegiatan dilaksanakan pada tanggal 20 Juni 2019 bertempat di Kelurahan Bandar Batauga Kecamatan Batauga Kabupaten Buton Selatan. Kesimpulan yang diperoleh petani dapat memahami tentang teknik budidaya terong dan cabe dan pemupukan menjadi hal terpenting dalam pertumbuhan tanaman.
\end{abstract}

Kata Kunci: Penyuluhan Laboratorium Lapangan Terong dan Cabe

\section{A. Pendahulan}

Kegiatan Laboratorium lapang Hortikultura sangat diperlukan untuk mendukung Visi Universitas Muhammadiyah Buton, laboratorium lapang tersebut selain sebagai pendukung proses belajar mengajar (PBM) dan pengabdian kepada masyarakat, juga dapat dijadikan sebagai etalase (show window). Keberadaan laboratorium lapang ini diharapkan dapat membangun image baru pada bidang pertanian, khususnya bagi petani dan para generasi muda tani, bahwa bidang pertanian tidak kalah dengan bidang yang lain, dapat menjadi profesi yang menarik, 
prospektif, dan terhormat. Dari beberapa hasil pengabdian masyarakat sebelumnya, laboratorium lapang mempunyai kelas lereng yang sangat beragam. Secara umum, didominasi oleh lereng agak miring/bergelombang dengan lereng (8-15\%) dengan luas lebih dari 50\% laboratorium lapang (Banuwa, dkk., 2011). Laboratorium lapang terpadu, dengan luas lebih kurang 0,5 ha. Laboratorium ini, sesuai dengan peruntukannya, digunakan untuk melakukan berbagai penelitian yang berkaitan dengan ilmu pertanian. Kondisi lereng dominan landai sampai bergelombang.

Kegiatan Penyuluhan dalam bentuk Laboratorium Lapangan Budidaya Terong dan Cabe adalah metode pelaksanaan penyuluhan budidaya terong dan cabe untuk petani dalam memperoleh pengetahuan tentang budidaya tanaman tersebut.

\section{B. Permasalahan}

Melihat kondisi petani yang ada di Kelurahan Bandar Batauga Kecamatan Batauga Kabupaten Buton Selatan yang mayoritas menanam tanaman hortikultura, maka yang menjadi permasalahan adalah:

1. Bagaimana Teknik Budidaya Terong dan Cabe yang baik.

2. Pengetahuan petani terong dan cabe yang masih minim.

\section{Metode Pelaksanaan}

Hardin, (2019: 32) bahwa kegiatan penyuluhan dilakukan dengan ceramah dan diskusi, sekaligus praktek lapangan. Jadi metode yang digunakan pada kegiatan pengabdian ini adalah melalui ceramah, tanya jawab, dan praktek langsung di lapangan. Metode cerama dan tanya jawab digunakan pada saat pemaparan materi oleh tim pengabdian. Di samping hal tersebut pendekatan yang ditawarkan pada pelaksanaan kegiatan pengabdian kepada masyarakat ini adalah dengan melakukan proses pelatihan/pendidikan orang dewasa, di mana para petani yang tergabung dalam kelompok tani akan diberikan pelatihan/pendidikan, guna memahami tentang teknik budidaya tanaman terong dan cabe yang tepat, sehingga memiliki perencanaan yang tepat dalam melakukan kegiatan usahataninya, agar dapat berkesinambungan (Faais Mufaasir Ramadhan, Hardin dan Indah Kusuma Dewi 2019: 17). 


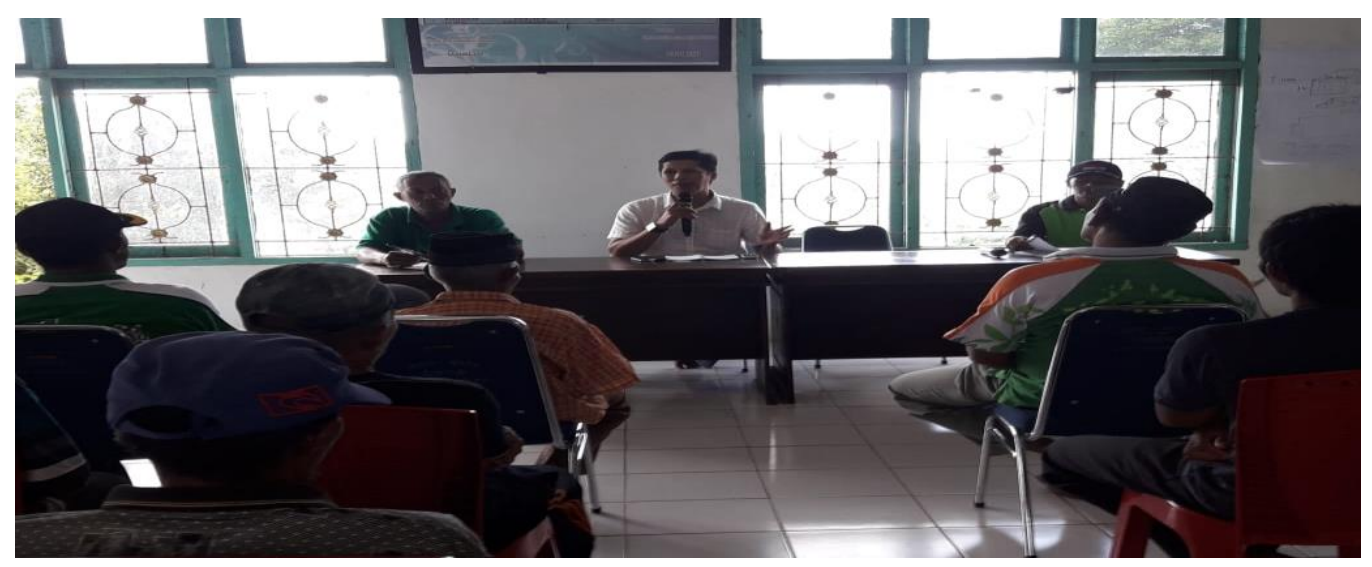

Gambar 1. Kegiatan Penyuluhan

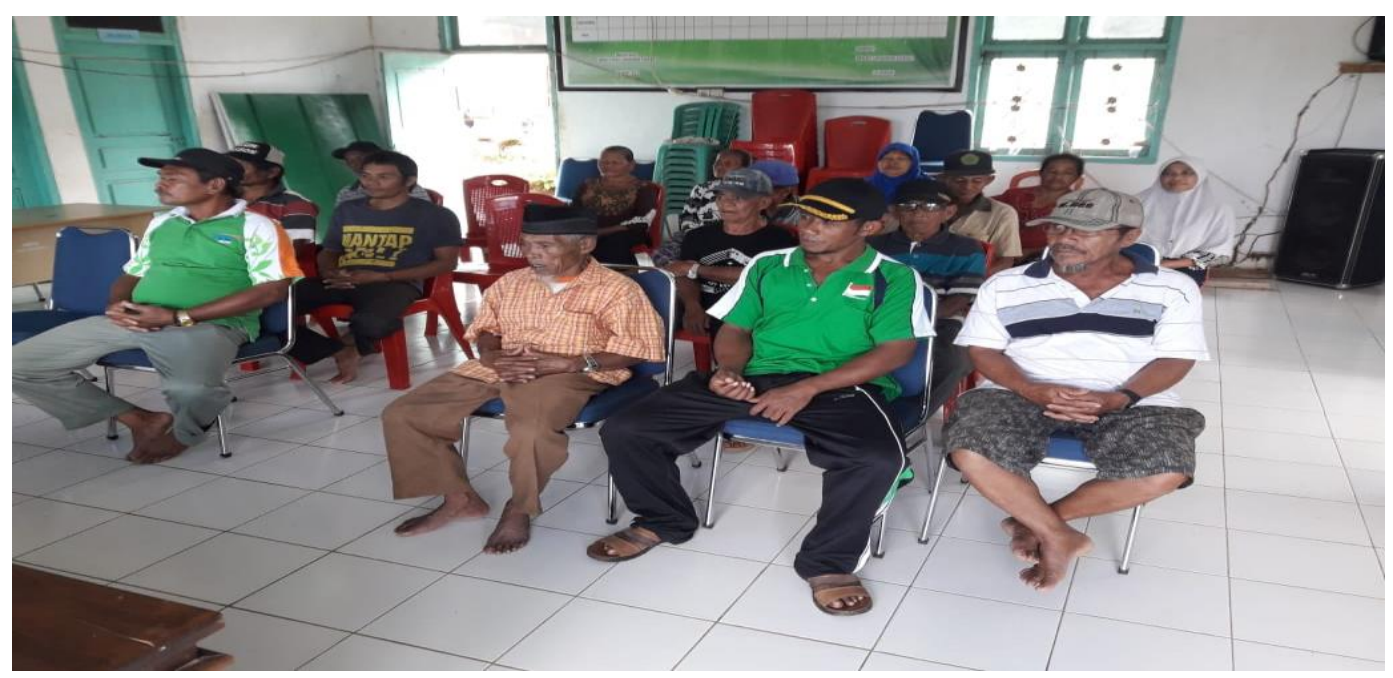

Gambar 2. Peserta Kegiatan Penyuluhan

\section{Pembahasan}

Kegiatan ini bermula dari observasi terhadap lahan hortikultura petani (Hardin dan Indah Kusuma Dewi, 2018: 37), kemudian mengundang petani untuk mengikuti kegiatan penyuluhan yang dilaksanakan oleh Pengabdi yang mengajarkan tentang:

\section{Teknik Budidaya Terong dan Cabe}

Aspek yang perlu anda perhatikan sebelum melakukan penanaman Terong dan Cabe adalah sebagai berikut:

\section{a. Tanaman terong (Eriyandi Budiman, 2008)}

Terong ungu merupakan tanaman yang tumbuh di daerah dengan iklim tropis. Di Indonesia, terong ungu digemari untuk di olah untuk menjadi sayur, atau bahan makanan 
lainnya. Ternyata terong ungu juga bisa di buat jadi obat-obatan. Untuk memulai budidaya terong ada beberapa hal yang dapat kita lakukan, yaitu:

\section{Memilih bibit}

Langkah pertama yang dapat kita lakukan untuk memulai budidaya terong ungu berbuah lebat adalah memilih bibit unggul. Saat ini sudah banyak toko yang menjual bibit unggul terong ungu, baik berbentuk benih maupun biji.

Berikut beberapa ciri yang dapat kita lihat untuk mengetahui benih terong ungu berkualitas yang dapat ditemukan di toko bibit:

a. Benih memiliki kadar air yang cukup.

b. Benih memiliki tampilan yang bersih dan mengilat.

c. Benih memiliki bentuk, ukuran, dan warna yang seragam.

d. Benih tidak tercampur dengan benih lain yang cacat/buruk.

e. Benih memiliki daya tumbuh yang cepat, yakni sekitar $80 \%$.

Jika ciri-ciri benih di atas sudah ada pada benih terong ungu yang kita pilih, maka kita siap untuk melangkah ke proses berikutnya, yakni penanaman.

\section{Menyiapkan media tanam}

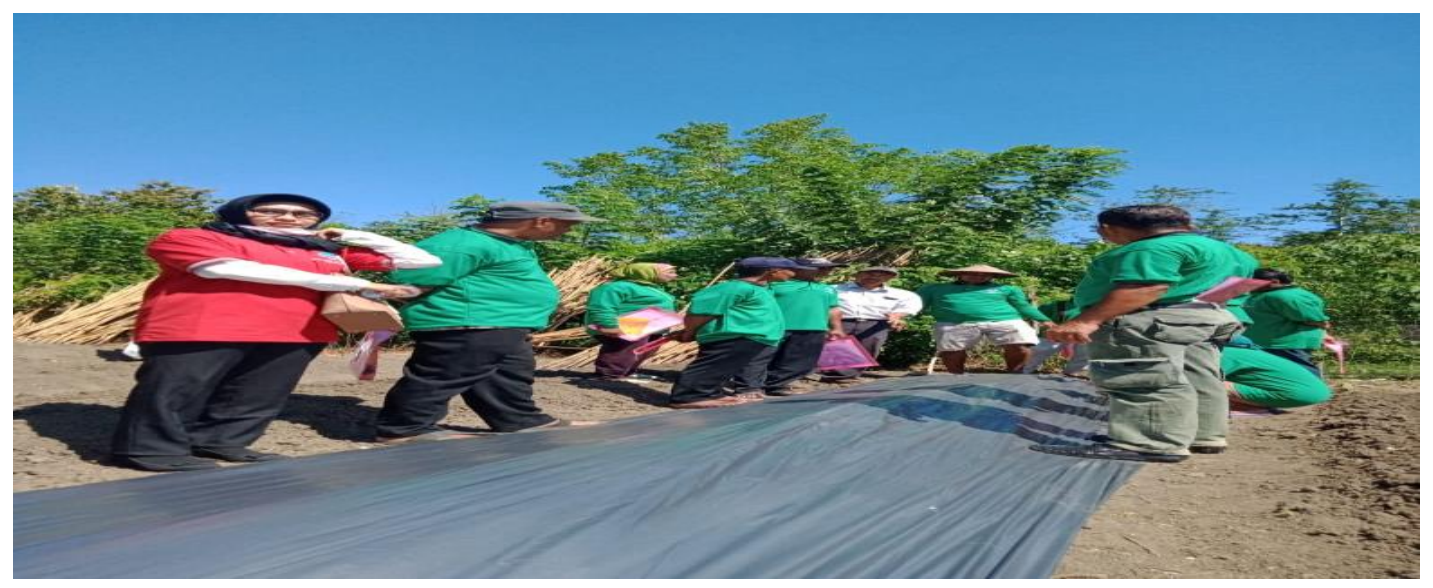

Gambar 3. Lokasi Persiapan Lahan

Jika ingin memiliki terong ungu berbuah lebat, kita harus menyiapkan media tanam yang baik karena media tanam sangat mempengaruhi pertumbuhan tanaman. Media tanam yang salah akan menghambat tumbuhnya tanaman dengan baik. Berikut beberapa langkah yang dapat dilakukan untuk menyiapkan media tanam bagi benih terong ungu: 


\section{Vol. 3 No. 2 Oktober 2019}

a. Menyiapkan polybag atau pot yang sudah diberi lubang secukupnya di bagian dasar. Sebaiknya kita menggunakan pot atau polybag berukuran besar agar nantinya penyemaian dapat dilakukan pada wadah yang sama. Hal ini akan sangat berguna bagi petani yang tidak memiliki lahan yang luas.

b. Memasukkan tanah ke dalam polybag atau pot tersebut. Dalam hal ini, kita harus memastikan bahwa tanah yang digunakan adalah tanah gembur yang kaya akan zat organik.

c. Mencampurkan tanah dengan padi sekam hingga rata. Perbandingan antara tanah dan padi sekam harus 1:1.

\section{Menyemai benih terong ungu}

Berikut langkah-langkah yang dapat dilakukan:

a. Pertama-tema, kita harus merendam benih terong ungu ke dalam air hangat selama kurang lebih 15 menit.

b. Membuatlah lubang-lubang tipis dengan jarak minimal $1 \mathrm{~cm}$ di atas campuran tanah dan padi sekam dalam polybag yang tadi telah disiapkan.

c. Memasukkan benih-benih terong pada lubang-lubang tersebut.

d. Menutup benih dengan sisa campuran tanah dan padi sekam.

e. Menepuk-nepuk tanah secara perlahan untuk memadatkannya.

f. Menyiram dengan air secukupnya. Penyiraman ini harus rutin dilakukan setiap pagi dan sore hari. Ingat pula untuk meletakkan polybag di tempat yang mendapat sinar matahari cukup.

\section{Memindahkan tanaman ke media tanam yang lebih besar}

Setelah masa semai, biasanya terong ungu membutuhkan waktu kurang lebih satu bulan agar ia mengalami pertumbuhan kecambah. Jika daun yang muncul sudah ada 4 helai, maka langkah selanjutnya adalah memindahkan bibit terong ke media tanam yang lebih besar. Jika tadi beberapa benih diletakkan dalam satu polybag/pot, dalam langkah ini, setiap polybag/pot hanya dapat diisi dengan satu bibit. Berikut langkah-langkahnya yang lebih rinci:

a. Menyiapkan polybag/pot sesuai jumlah bibit.

b. Mencampurkan media tanah dengan pupuk kandang dan padi sekam, lalu masukkan ke dalam polybag/pot yang tersedia.

c. Membuat lubang di tengahnya dengan kedalaman kurang lebih $5 \mathrm{~cm}$, lalu tanam bibit terong ungu di lubang tersebut. 
d. Menepuk-nepuk tanah secara perlahan untuk membuatnya padat.

e. menyiram dengan air secukupnya.

b. Tanaman Cabe

1. Menanam cabai rawit dapat tumbuh pada dataran rendah hingga ketinggian 1.300 dpl. Saat anda memilih daerah dataran tinggi usahkan menanam bibit yang dapat dengan mudah adaptif terhadap dataran tinggi.

2. Menanam cabai dapat tumbuh dengan baik pada iklim yang tidak terlalu dingin serta tidak terlalu lembab. Usahakan untuk memilih iklim 25-30 $\mathrm{C}$ karena tanaman cabai dapat tumbuh dengan baik.

3. Memilih tanah yang memiliki ph berkisar $6,5-6,8$ karena sangat baik bagi tanaman cabai rawit.

4. Membentuk tanah datar sangat cocok untuk pembudidayaan tanam cabai rawit dengan sudut kemiringan lahan $0-10^{\circ}$.

5. Menempatkan di tempat terbuka, tujuannya agar tanaman selalu terkena sinar matahari.

6. Jika anda ingin menggunakan lahan bekas tanaman padi malah lebih baik.

7. Jika didaerah anda hanya ada tanah tegalan tidak masalah asal selalu ada air untuk penyiraman.

\section{Melakukan Pengolahan Media Tanam}

Cara menanam cabai rawit selanjutnya adalah pengolahan media tanam, karena kita ketahui bahwa media tanam merupakan hal mutlak yang harus disiapkan sebelum melakukan budidaya tanaman. Sebelum kita masuk ke tahap pengolahan ada baik anda pahami jenis-jenis media tanam sebagai berikut:

1. Menggunakan arang, media ini berfungsi sebagai pemikat air yang tinggi, media ini sangat cocok untuk tanaman anggrek karena hidup didaerah kelembaban tinggi.

2. Menggunakan tanah liat kita ketahui bahwa tanah liat termaksud tanah yang memiliki tekstur halus serta memiliki pori-pori yang sangat kecil, sehingga dapat mengikat air dalam jumlah yang banyak.

3. Vermikulit dan perlit. Vermikulit adalah media anorganik steril yang dihasilkan dari pemanasan kepingan-kepingan mika dan mengandung potassium. 


\section{Vol. 3 No. 2 Oktober 2019}

4. Gabus (styrofoam). Styrofoam adalah bahan anorganik yang terbuat dari kopolimer styren yang bisa dijadikan sebagai pilihan media tanam

Setelah memahami jenis-jenis media tanam, langsung saja kita masuk ke tahap pengolahan media tanam sebagai berikut:

1. Pertama anda harus mencangkul atau membajak tanah, kegiatan ini bertujuan untuk menghilangkan bekas tanaman sebelumnya.

2. Mengecek kondisi $\mathrm{pH}$ tanah, jika terlalu tinggi gunakan kapur untuk menstabilkan tanah.

3. Selanjutnya proses pemberian pupuk, kami sarankan untuk menggunakan pupuk kandang karena terbilang alami.

4. Setelah proses pemupukan, anda harus tentukan berapa banyak ingin melakukan budidaya tanaman cabai karena tahap kali ini kita akan membuat bedengan agar mempermudah proses penanaman maupun panen nanti.

5. Tahap selanjutnya membungkus bedengan dengan plastik lalu buat lubang sebagai tempat peletakan bibit cabai, beri jarak $50-60 \mathrm{~cm}$ perlubang.

6. Mendiamkan bedengan tadi selama 1 sampai 2 minggu agar pupuk dapat meresap ke tanah dengan baik

\section{Pemilihan bibit cabai rawit berkualitas}

Pemilihan bibit cabai rawit yang berkualitas merupakan salah satu faktor penentu hasil panen karena jika bibit yang digunakan berkualitas buruk tentu tanaman cabai akan menghasilkan buah cabai yang buruk pula. Oleh sebab itu kami akan memberikan cara memilih bibit cabai rawit berkualitas sebagai berikut:

- pilih buah yang dipetik pada cabang paling bawah, karena dapat tumbuh dengan cepat

- selanjutnya pilih buah yang benar-benar masak

- pilih buah yang berukuran lebih besar dari normalnya

- buah tidak mengalami cacat maupun serangan hama

selain cara diatas kalian juga bisa membeli bibit buah cabai seperti Tanindo, Panah merah usahakan untuk membeli pada toko pertanian resmi.

Melakukan penyemaian bibit cabai rawit 
Sebelum melakukan proses penanaman bibit cabai ada baiknya anda melakukan penyemaian, bertujuan agar saat bibit ditanam bisa langsung tumbuh tanpa harus melewati proses adaptasi. Cara melakukan penyemaian sebagai berikut:

- Ambil bibit cabai rawit yang sudah anda beli atau buat sendiri

- Gunakan polybag dengan diameter $5 \mathrm{~cm}$

- Gunakan pupuk kandang yang sudah disaring sehingga hanya butiran halus yang digunakan serta siapkan tanah dengan perbandingan 1:3 lalu aduk sampai rata

- Setelah itu, anda hanya perlu menyiram media semai tadi dengan air secukupnya lalu diamkan beberapa hari

- Setelah semua selesai, letakkan bibit cabai satu persatu kedalam polybag dan tunggu sampai tumbuh tunasnya

\section{Cara menanam cabai rawit}

Setelah bibit cabai rawit berumur 4 minggu atau sudah tumbuh daunnya kira kira 2 sampai 4 daun anda bisa memindahkan bibit kemedia tanaman yang sudah disiapkan sebelumnya.

Masukkan bibit cabai rawit disetiap lubang yang telah disiapkan dengan jarak 5-6 cm per lubang, lalu usahakan untuk menanam pada pagi hari untuk menghindari tanaman cepat layu. Setelah semua selesai beri pupuk kandang dan air secukupnya.

\section{Melakukan perawatan cabai rawit}

Cara menanam cabai rawit selanjutnya adalah proses perawatan bertujuan agar tanaman dapat tumbuh dan berbuah secara maksimal. Berikut ini adalah cara yang bisa anda lakukan : Asupan air yang cukup

Seringnya permasalahan yang muncul seperti rontok bakal buah, layu cabang, dikarenakan asupan air yang kurang itu semua karena penyiraman air yang kurang. Perawatan tanaman cabai rawit

Langkah selanjutnya adalah

- Siapkan polybag/pot sesuai jumlah bibit.

- Campurkan media tanah dengan pupuk kandang dan padi sekam, lalu masukkan ke dalam polybag/pot yang tersedia.

- Buat lubang di tengahnya dengan kedalaman kurang lebih $5 \mathrm{~cm}$, lalu tanam bibit terong ungu di lubang tersebut. 
- Tepuk-tepuk tanah secara perlahan untuk membuatnya padat.

- Siram dengan air secukupnya.

b. Tanaman Cabai (Soewito Brotoadji, 2012)

- Tanaman cabai rawit dapat tumbuh pada dataran rendah hingga ketinggian 1.300 dpl. Saat anda memilih daerah dataran tinggi usahkan menanam bibit yang dapat dengan mudah adaptif terhadap dataran tinggi.

- Tanaman cabai dapat tumbuh dengan baik pada iklim yang tidak terlalu dingin serta tidak terlalu lembab. Usahakan untuk memilih iklim $25-30^{\circ} \mathrm{C}$ karena tanaman cabai dapat tumbuh dengan baik.

- Pilih tanah yang memiliki ph berkisar 6,5-6,8 karena sangat baik bagi tanaman cabai rawit

- Bentuk tanah datar sangat cocok untuk pembudidayaan tanam cabai rawit dengan sudut kemiringan lahan $0-10^{\circ}$

- Tempat terbuka, tujuannya agar tanaman slalu terkena sinar matahari

- Jika anda ingin menggunakan lahan bekas tanaman padi malah lebih baik

- Jika didaerah anda hanya ada tanah tegalan tidak masalah asal selalu ada air untuk penyiraman. 


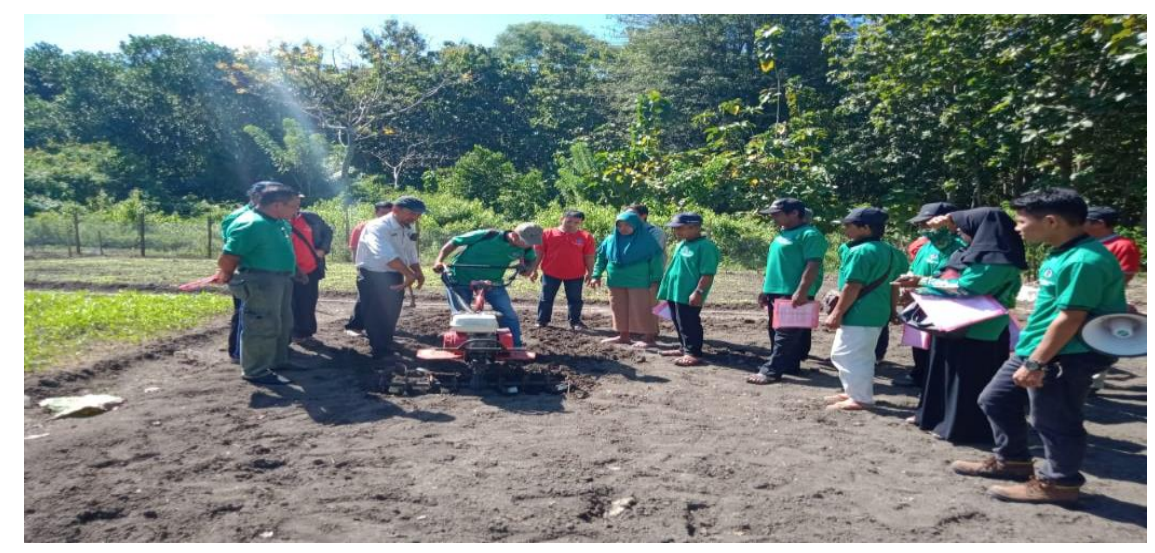

Gambar: 4 Pengolahan Media Tanam

- Pertama anda harus mencangkul atau membajak tanah, kegiatan ini bertujuna untuk menghilangkan bekas tanaman sebelumnya

- Cek kondisi ph tanah, jika terlalu tinggi gunakan kapur untuk menstabikalkan tanah.

- Selanjutnya proses pemberian pupuk, kami sarankan untuk menggunakan pumpuk kandang karena terbilang alami serta tidak merupakan ph tanah

- Setelah proses pemupukan, anda harus tentukan berapa banyak ingin melakukan budidaya tanaman cabai karena tahap kali ini kita akan membuat bedengan agar mempermudah proses penanaman maupun panen nanti.

- Tahap selanjutnya bungkus bedengan dengan plastik lalu buat lubang sebagai tempat peletakan bibit cabai, beri jarak 50-60 cm perlubang.

- Diamkan bedengan tadi selama 1 sampai 2 minggu agar pupuk dapat meresap ke tanah dengan baik

\section{Pemilihan Bibit Cabe Rawit}

pemilihan bibit cabai rawit yang berkualitas merupakan salah satu faktor penentu hasil panen karena jika bibit yang digunakan berkualitas buruk tentu tanaman cabai akan menghasilkan buah cabai yang buruk pula. Oleh sebab itu kami disini akan memberikan cara memilih bibit cabai rawit berkualitas sebagai berikut :

- pilih buah yang dipetik pada cabang paling bawah, karena dapat tumbuh dengan cepat

- selanjutnya pilih buah yang benar-benar masak

- pilih buah yang berukuran lebih besar dari normalnya 
- buah tidak mengalami cacat maupun serangan hama

selain cara diatas kalian juga bisa membeli bibit buah cabai seperti Tanindo, Panah merah usahakan untuk membeli pada toko pertanian resmi.

\section{Penyemaian Bibit Cabe Rawit}

Sebelum melakukan proses penanaman bibit cabai ada baiknya anda melakukan penyemaian, bertujuan agar saat bibit ditanam bisa langsung tumbuh tanpa harus melewati proses adaptasi. Cara melakukan penyemaian sebagai berikut:

- Ambil bibit cabai rawit yang sudah anda beli atau buat sendiri

- Gunakan polybag dengan diameter $5 \mathrm{~cm}$

- Gunakan pupuk kandang yang sudah disaring sehingga hanya butiran halus yang digunakan serta siapkan tanah dengan perbandingan 1:3 lalu aduk sampai rata

- Setelah itu, anda hanya perlu menyiram media semai tadi dengan air secukupnya lalu diamkan beberapa hari

- Setelah semua selesai, letakkan bibit cabai satu persatu kedalam polybag dan tunggu sampai tumbuh tunasnya

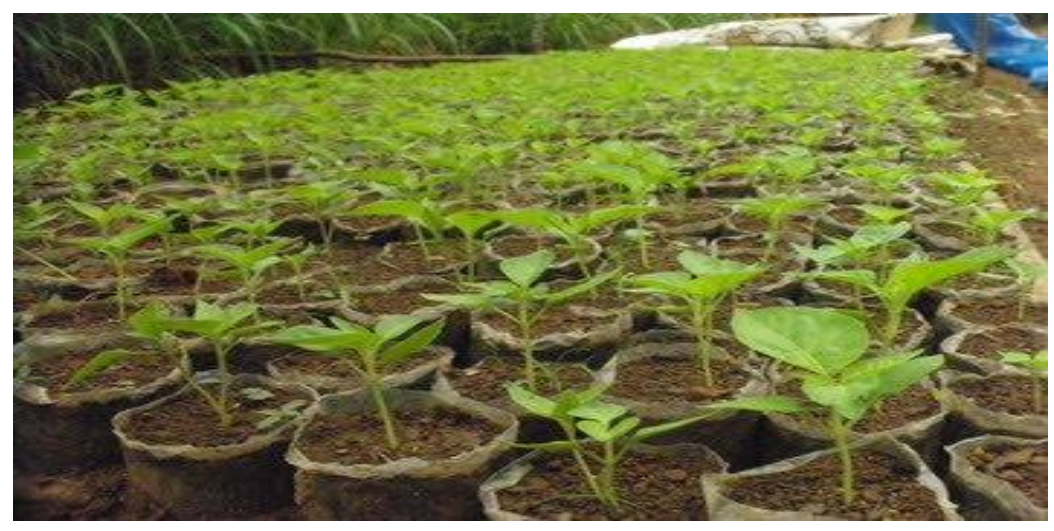

Gamabar: 5 Hasil pembibitan

\section{Cara Menanam Cabai Rawit}

Setelah bibit cabai rawit berumur 4 minggu atau sudah tumbuh daunnya kira kira 2 sampai 4 daun anda bisa memindahkan bibit kemedia tanaman yang sudah disiapkan sebelumnya.

Masukkan bibit cabai rawit disetiap lubang yang telah disiapkan dengan jarak 5-6 cm per lubang, lalu usahakan untuk menanam pada pagi hari untuk menghindari tanaman cepat layu. Setelah semua selesai beri pupuk kandang dan air secukupnya. 


\section{E. Kesimpulan}

Berdasarkan hasil kegiatan Penyuluhan budidaya terong dan cabe rawit diperoleh beberapa kesimpulan sebagai berikut:

1. Petani mampu menghitung populasi tanaman dan memprediksi jumlah pohon.

2. Peserta pelatihan menyadari akan inovasi teknologi serta pemanfaatan alat pertanian.

3. Pemupukan sangat dibutuhkan dalam proses pertumbuhan tanaman terong dan cabe.

\section{DAFTAR PUSTAKA}

Banuwa dkk, 2011. Karakteristik Lahan Laboratorium Lapang Terpadu. Fakultas Pertanian UNILA. Bandar Lampung.

Eriyandi Budiman, 2008. Cara dan Upaya Budidaya Terong. CV. Wahana Iptek. Bandung

Faais Mufaasir Ramadhan, Hardin, Indah Kusuma Dewi (2019). Teknik Budidaya Kakao Pada Kelompok Tani Kakao di Kelurahan Waliabuku Kota Baubau. Jurnal Pengabdian Kepada Masyarakat MEMBANGUN NEGERI, 2(1), 14-26. https://jurnalumbuton.ac.id/index.php/ppm/article/view/198/149

Fadli Irsyad, Eri Gas Ekaputra, Assyaukani. (2019). Kajian Perubahan Iklim Pada Penentuan Jadwal Tanam Cabai di Kabupaten Agam. Jurnal Teknologi Pertanian Andalas, 2019; 23 (1): 91-102.

Fauzi Chairani. (2017). Studi Pendahuluan Respon Bibit Terong KB Terhadap Pemupukan Melalui Daun. Buletin Penelitian Tanaman Rempah dan Obat, 2017; 4(2): 59-63.

Hardin. (2019). Pembinaan Pengurus Persaudaraan Beladiri Kempo Indonesia (Perkemi) Dojo Sorawolio Dalam Melaksanakan Peran dan Fungsi Manajemen Organisasi. Jurnal Pengabdian Kepada Masyarakat MEMBANGUN NEGERI, 2(1), 27-36.

Hardin dan Indah Kusuma Dewi, (2018). Pengorganisasian Petani Untuk Menanam Bawang Merah di Kelurahan Kaisabu Baru Kecamatan Sorawolio Kota Baubau. Jurnal Pengabdian Kepada Masyarakat MEMBANGUN NEGERI, Vol. 2 No. 1 April 2018.

Soewito Brotoadji, 2012. Bertanam Cabai. Araska. Yogyakarta 